\title{
Dor como motivo de busca para assistência ao trabalho de parto hospitalar
}

\author{
Maria de Lourdes Silva Marques Ferreira ${ }^{1}$, Thais Érika Giaxa ${ }^{2}$, Regina Célia Popim ${ }^{3}$, Silmara Meneguin ${ }^{4}$
}

\author{
${ }^{1}$ Enfermeira, Doutora em Enfermagem. \\ Professora Assistente Doutor da \\ Universidade Estadual Paulista Júlio de \\ Mesquita Filho. Botucatu, SP, Brasil. E-mail: \\ malusa@fmb.unesp.br. \\ ${ }^{2}$ Enfermeira, Mestre em Enfermagem. \\ Enfermeira do Serviço Móvel de \\ Emergência do município de Marília. \\ Marília, SP, Brasil. E mail: \\ thaiserika@hotmail.com. \\ ${ }^{3}$ Enfermeira, Doutora em Enfermagem. \\ Professora Assistente Doutor da \\ Universidade Estadual Paulista Júlio de \\ Mesquita Filho. Botucatu, SP, Brasil. E-mail: \\ rpopim@fmb.unesp.br. \\ ${ }^{4}$ Enfermeira, Doutora em Cardiologia. \\ Professora Assistente Doutor da \\ Universidade Estadual Paulista Júlio de \\ Mesquita Filho. Botucatu, SP, Brasil. E-mail: \\ silmeneguin@fmb.unesp.br.
}

Recebido: 16/05/2016.

Aceito: 01/12/2016.

Publicado: 15/05/2017.

\section{RESUMO}

O estudo objetivou compreender a influência da dor como motivo de busca para assistência ao trabalho de parto hospitalar. Utilizou-se a abordagem fenomenológica socioexistencial, proposta por Schütz. Participaram do estudo nove gestantes conduzidas à maternidade, no período de fevereiro a junho de 2013. A entrevista norteou-se pelas questões: Conte-me como a dor influenciou sua decisão de procurar o hospital. Qual o significado da dor para você nesta fase da gestação? Os discursos foram submetidos à análise ideográfica e nomotética, em que emergiram as seguintes categorias: identificação da dor, dor com perdas vaginais, permanência e progressão da dor, influência de familiares para a identificação da dor. O estudo possibilitou compreender a influência da dor na complexidade do trabalho de parto, tendo em vista sua subjetividade e multifatoriedade. Evidenciou-se também que nem sempre é possível racionalizar acerca da dor em virtude do meio sociocultural no qual a gestante está inserida.

Descritores: Trabalho de Parto; Gestantes; Dor; Enfermagem Obstétrica.

\section{INTRODUÇÃO}

Historicamente, desde os primeiros tempos, a gestação, nascimento e parto dos seres humanos foram sempre situações de mobilização pessoal e social, envolvidas por tabus, ritos e preconceitos e apresentando grande significado e fascínio, pois se relacionam à continuidade da vida e perpetuação da espécie ${ }^{(1)}$.

Considera-se que as crenças sobre a gestação influenciam o modo como a gestante se cuida e como é cuidada pela família e pessoas de seu convívio social. Sendo assim, a mulher, ao descobrir-se grávida, cumpre 
uma série de normas concebidas culturalmente ${ }^{(2)}$.

Fisiologicamente, o término da gravidez é caracterizado por dores decorrentes das contrações ${ }^{(3)}$. O útero grávido apresenta contrações desde o início e, a partir da 28a à 30a semana, começam a ser percebidas pela gestante, ainda indolores. Estas são as contrações Braxton-Hicks. À medida que a gestação evolui, as contrações são mais frequentes e coordenadas para amadurecimento do colo uterino ${ }^{(4)}$.

O verdadeiro trabalho de parto acontece com contrações uterinas ritmadas em intervalos regulares que aumentam em frequência e intensidade, não diminuindo com repouso. Apresenta apagamento do colo, dilatação cervical, formação das bolsas de águas, emissão de mucosidade e contrações rítmicas, ocorrendo duas contrações em 10 minutos, com duração de 20 a 60 segundos ${ }^{(5)}$.

Na dor relacionada ao falso trabalho de parto há a sensação de desconforto, mas que não progride na intensidade, duração e dilatação do colo uterino ${ }^{(6)}$. No entanto, a dor identificada pela gestante é, muitas vezes, desconhecida e pode motivá-la a buscar precocemente a assistência hospitalar. Além disso, há que se considerar também que a dor do parto é uma experiência única, subjetiva e influenciada por fatores socioeconômicos e culturais. No entanto, apesar da relevância da temática ainda é um tema pouco explorado na literatura e, consequentemente, pouco valorizado pelos profissionais de saúde.

Diante do exposto, pergunta-se: Quais os motivos que levam as gestantes a procurar assistência obstétrica antes de instituído o verdadeiro trabalho de parto? Quais os sinais identificados pelas gestantes que as levam a solicitar a viatura do Serviço de Assistência Móvel de Urgência (SAMU)?

Este estudo objetivou compreender a influência da dor como motivo de busca para assistência ao trabalho de parto hospitalar.

\section{MÉTODOS}

Este estudo foi estruturado a partir da abordagem qualitativa de delineamento pautado na linha da fenomenologia social, uma vez que o interesse de pesquisa se encontra no processo e na forma como o fenômeno se manifesta. A pesquisa qualitativa incorpora a questão do significado e intencionalidade como inerentes aos atos, relações e estruturas sociais ${ }^{(7)}$.

Utilizou-se como fio condutor para compreensão dos significados o pensamento do sociólogo e fenomenólogo Alfred Schütz, para quem a conduta humana é ciência simples e particular ${ }^{(8)}$. Para esse autor, a ação humana é projetada pelo homem de forma consciente e intencional e carrega, em seu bojo, dois motivos: "motivos para", que instigam a ação e, portanto, são direcionados para o futuro e "motivos porque", que são evidentes nos fatos transcorridos e imutáveis, mas influenciam a ação presente ${ }^{(9)}$.

Desse modo, a fenomenologia social busca conhecer e organizar o que é vivido pelos indivíduos nas relações cotidianas, em seus entendimentos e desavenças, o que configura grupo social com especificidades $^{(8)}$.

A investigação foi realizada em 2013, num hospital filantrópico de município do interior do Estado de São Paulo que atende as gestantes de baixo risco obstétrico. A amostra constituiu-se por gestantes que 
terminaram as consultas pré-natais e foram levadas à maternidade, pelo SAMU, por perceberem que estavam em trabalho de parto.

Foram realizadas entrevistas semiestruturadas, na sala de reuniões da maternidade, após a consulta obstétrica, a partir das questões norteadoras: Conte-me como a dor influenciou a sua decisão de procurar o hospital. Qual o significado da dor para você nesta fase da gestação? As entrevistas foram gravadas após assinatura do termo de consentimento livre e esclarecido. O estudo foi aprovado pelo Comitê de Ética e Investigação em Pesquisa do referido município, sob no 597/08. A coleta de dados foi encerrada quando as entrevistas não apontaram mais elementos novos, segundo o critério da saturação teórica ${ }^{(10)}$.

A análise dos depoimentos se deu, primeiramente, pela leitura atentiva dos discursos com o propósito de apreender o sentido do todo. Em seguida, os discursos foram relidos para elaboração das unidades de significados e para a redução fenomenológica, que é a elaboração da linguagem do pesquisador. Passou-se, em seguida, à análise ideográfica, análise individual, nomotética e à análise geral dos discursos, resultando nas convergências, divergências e idiossincrasias ${ }^{(10)}$.

\section{RESULTADOS}

A amostra foi constituída por gestantes entre 20 e 22 anos de idade, a maioria em união estável e na 39a semana. Uma em cada duas era primigesta; todas realizaram mais de seis consultas pré-natais, mas somente uma participou de curso de preparação para o parto.

Quanto à frequência de vezes que compareceram à maternidade em falso trabalho de parto, a maioria delas o fazia pela terceira vez.

Nos discursos das mulheres da pesquisa, a dor foi indicação relevante para a tomada de decisão baseada em experiências anteriores, revelando o "motivo porque" ou razão da ação que motivou a busca pela assistência hospitalar.

Dos relatos das mulheres sobre o motivo da procura precoce da maternidade relacionado à dor do trabalho de parto emergiram quatro categorias abaixo relatadas:

\section{Categoria 1. Identificação da dor}

Os resultados obtidos possibilitaram perceber que a existência de um estoque de conhecimentos à mão, previamente constituído, orienta as ações das gestantes na procura pela maternidade, conforme se pode apreender dos discursos:

Eu estava lavando roupa, depois do almoço, e senti aquela dorzinha. Eu já acordei meio esquisita; parecia que estava abrindo as costas, a barriga dura. Eu não perdi líquido, mas pensei: acho que está na hora (E1).

É que eu estava com dor de madrugada, assim aqui embaixo. Aí, eu falei assim pra minha amiga: acho que está chegando a hora; é uma dor que parece que ele está querendo sair. Hoje estou com dor no pé da barriga que vai indo para as costas (E3).

[...] já é a terceira vez que eu venho e o médico falou que tinha que ficar mais forte, que a dor estava muito fraca (E5). 
Nas falas das gestantes é possível perceber a influência das informações recebidas dos profissionais de saúde em relação aos sinais do trabalho de parto e como isso influenciou a busca pela assistência hospitalar.

[...] o médico do posto explicou que era uma dor que vinha das costas e é essa dor que eu estou sentindo. Pensei: se é essa dor, eu tenho que ir. (E5).

\section{Categoria 2. Dor com perdas vaginais}

As gestantes expressam que a dor sentida, além de apresentar intensidade maior do que conseguem suportar, envolve um caráter limitante quando as impede de realizar tarefas cotidianas e de suprir suas necessidades humanas básicas, como segue:

Eu vim com dor. Já começou hoje, mas estava fraquinha. No jantar, eu nem quis comer; deu a dor forte de novo. Aí, eu tinha certeza que tinha que vir pra cá; tomei um banho rapidinho e pedi pra minha mãe chamar a ambulância (E8).

[...] contração, mas muito longe uma da outra tipo. Aí eu fiquei até a noite com essa dorzinha, tipo uma hora. Aí eu fui no culto né, ai chegou lá, aí eu fui no banheiro, aí saiu um catarro, assim, transparente (E6).

Eu já tinha vindo, porque eu estava perdendo líquido, eu não estava com dor, não. Ai, eu pensei: acho que isso é a bolsa que estourou. Aí, eu vim e eles falaram que era só aquele corrimento, aquela, como chama, aquela secreção da vagina (E7)?

Neste lado aqui, não consigo mexer, eu vou direto ao banheiro fazer xixi, direto, e essa dor não para; ela está cada vez mais forte; o corrimento saiu primeiro, tipo um catarro, e depois sai água, toda hora tem que ficar indo no banheiro (E9).

\section{Categoria 3. Permanência e progressão da dor}

Reconhecer o trabalho de parto, após momentos de dúvida e reflexão, foi resultado da permanência ou progressão da dor, mesmo depois das estratégias de enfrentamento que buscaram em sua bagagem de conhecimentos adquiridos. O repouso, recursos de hidroterapia e até mesmo medicações foram realizadas para se alcançar esse propósito, como se segue:

[...] então, eu cheguei em casa, tomei um banho e deitei. Mas a dor só foi piorando; eu estava ficando inquieta, rolando de dor. Então, eu não aguentei; eu vim pra cá de novo (E7).

Já é a terceira vez que eu venho. O médico falou que tinha que ficar mais forte. Quando foi de madrugada, apertou mais, mas agora de manhã eu não aguentava. Daí, pensei: não vou aguentar. Aí eu vim. É uma dor que começa bem fraquinha nas costas, vem pra barriga e ela começa a ficar dura, assim, e aí vai aumentando a dor (E5).

É eu vim, mas falaram que é pra eu voltar... eu não queria mais voltar pra casa assim; queria ganhar e pronto, acabar logo com isso... está muito pesado, estou cansada. Eu não aguento mais esse calor... quero ganhar logo (E1).

[...] eu achei que estava em trabalho de parto, mas eles falaram que é pra eu esperar as dores fortes, que pode ser que estoure a bolsa, ou não (...) mas eu estou com dor desde ontem (E1).

[...] aí quando foi de madrugada apertou mais; aí eu esperei de manhã (...) mas agora de manhã, não estava aguentando; aí eu vim. É uma dor que começa fraquinha nas costas, vem pra barriga e começa a ficar dura assim, e aí vai aumentando a dor! (E5).

[...] aí a hora que nós estávamos subindo, aumentou a dor. Quando cheguei lá na casa da minha amiga, tinha aumentado bastante. Estava dando uma dor super forte; aí foi por causa da contração; fica doendo as costas e depois endurece com dor mais forte ... (E4).

As gestantes acreditavam que, naquele momento da procura pela maternidade, estivessem em 
trabalho de parto verdadeiro, o que não foi diagnosticado no exame obstétrico, ficando então configurado o falso trabalho de parto, tendo a dor como sinal.

\section{Categoria 4. Influência de familiares para a identificação da dor}

$\mathrm{Na}$ gestação, as mulheres recebem informações a respeito da dor do parto, porém o conhecimento popular transmitido por familiares e amigos possui um valor cultural importante e este é, muitas vezes, determinante.

Eu vim porque estou com dor, assim no pé da barriga. É porque ela (avó) fala: "a dor é uma cólica, só que é forte", e eu, como já tinha tido cólica e ficava de cama, então, eu pensei: acho que é aquilo (E3).

A minha sogra disse que quando ela teve o dela, estourou a bolsa, saiu água que escorreu pela perna dela. Ela veio, deu três dor e ele nasceu. Quase nem deu tempo (E5).

Mulheres com laços de parentesco ou amizade e que já tinham vivenciado a dor de parto transmitem suas experiências e até mesmo de forma negativa:

[...] Todo mundo fala da dor do parto, que dói, que é a dor da morte, que você morre e nasce de novo, todo mundo; minha mãe mesmo fala que tem até dó de mim, mas ela fala assim que depois vale a pena; nasce acaba tudo a dor, mas eu ainda tenho medo (E2).

[...] tenho medo dessa dor forte que eles falam; estou sozinha (E7).

Então, eu imagino que dor de barriga seja diferente da dor do parto, mas o que minha irmã falava é que estava com dor de barriga e ficava o tempo todo no banheiro, e ela fazia necessidade mesmo. Aí, quando ela chegou no médico ela já estava de 10 dedos (E6).

[...] a minha cunhada fala que doía, que era a pior dor, que ela tinha vontade de bater em todo mundo; cada um fala uma coisa, e eu fico assim, com medo, preocupada (E5).

\section{DISCUSSÃO}

Apesar dos avanços tecnológicos da obstetrícia e recursos da assistência ao parto este continua sendo assustador, pelos inúmeros significados aliados à dor, ao sofrimento e à angústia ${ }^{(11)}$.

Em situação de parto e nascimento a contração uterina, conhecida popularmente como dor de parto, é um componente biológico e fisiológico do processo de parturição. Por ser um fenômeno universal e presente no nosso cotidiano, a presença da sensação dolorosa é a causa apontada com maior frequência pelas pessoas como motivação da busca de assistência médica. É percebida como sintoma, portanto um fenômeno único e exclusivo da parturiente ${ }^{(12)}$.

As mulheres participantes deste estudo perceberam a dor nas mais variadas intensidades como o "start" para busca da maternidade. As gestantes acreditavam que as perdas vaginais, a permanência e progressão da dor, sinalizavam para o trabalho de parto verdadeiro. A perda da Rolha de Schoeder, secreção mucóide que, durante toda gestação protege o canal cervical e pode ser percebida como perda vaginal até duas semanas anteriores ao parto, foi identificada como precursor do processo parturitivo.

A dor do parto é vista pela gestante como a forma natural do processo de nascimento e que a motiva pela busca de assistência hospitalar. Ressalta-se que a tomada de decisão é influenciada pelas múltiplas 
fontes de informações que a mesma recebe e que interferem neste processo ${ }^{(13-14)}$. Além disso, há que se considerar a lacuna existente entre a última consulta preconizada na rede de atenção básica no pré-natal e o nascimento. Nesse período, a gestante fica codependente do sistema, requerendo uma relação mais afetiva que minimize a ansiedade presente naquele momento ${ }^{(15)}$.

Neste contexto, é de fundamental importância a informação dada pelos profissionais de saúde durante as etapas do pré-natal ${ }^{(16)}$. Por outro lado, percebe-se pelas falas das gestantes que há uma insuficiência de informações que as colocam numa situação de fragilidade e dependência do serviço de saúde, principalmente neste intervalo de conclusão do pré-natal e a espera do momento do parto. Nesse sentido, é primordial uma comunicação efetiva com linguagem acessível e interativa entre profissionais e usuárias com criação de vínculos para que dúvidas sejam dirimidas e resignificadas ${ }^{(16)}$.

No entanto, a influência de leigos neste processo de reconhecimento de sinais e sintomas e também na busca pela assistência foi desvelada nesta pesquisa. Os familiares têm papel importante não somente como transmissor de informações, mas também pelo acolhimento e tranquilidade que proporcionam à gestante diante dos sentimentos gerados pela proximidade do trabalho de parto ${ }^{(17)}$. As pessoas das relações familiares, que transmitem as informações negativas em relação à dor de parto, com base nas suas vivências, são aquelas que as gestantes buscam apoio.

Estudo realizado no Egito mostrou que maioria das mulheres grávidas recorrem a familiares e amigos como fonte primária de informação ${ }^{(18)}$. Todavia, a insegurança da gestante e a influência de familiares e amigos neste momento as levam a uma trajetória que produz uma peregrinação sofrida e desnecessária ${ }^{(19)}$.

O conteúdo das informações sobre a dor de parto recebido pelas gestantes, do meio social, cotidiano e de suas relações familiares podem gerar diversos sentimentos, como dúvida, descrença, incredulidade, curiosidade, medo e resignação. Esses sentimentos relacionados à dor de parto e identificados pelas gestantes como citados alteram-se constantemente, um substituindo o outro de forma dinâmica, sempre na dependência das informações obtidas e/ou vivenciadas pelas mulheres no desenvolver da gravidez. Há a alternância de sentimentos, contudo, a dor de parto é, com maior frequência, caracterizada como sendo extremamente negativa e, por conseguinte, o medo predomina ${ }^{(20)}$.

Apesar de os avanços da medicina possibilitarem que a dor do parto seja minimizada ainda é um tabu e uma realidade a ser enfrentada ${ }^{(21)}$. Em pesquisa qualitativa realizada com 31 gestantes na Suécia o medo foi desvelado como um forte sentimento ligado ao trabalho de parto ${ }^{(22)}$.

Em outro estudo realizado com 45 gestantes no último trimestre da gestação, durante o atendimento pré-natal em município de Santa Catarina evidenciou que o medo da dor do parto esteve fortemente representado no imaginário das gestantes e transformou-se com a proximidade do parto ${ }^{(23)}$, como corroborado nesta pesquisa.

O fato das gestantes terem procurado o serviço de saúde acreditando estar em trabalho de parto e após avaliação do profissional de saúde terem sido dispensadas para retornarem a suas casas, como evidenciado nos relatos, configurou que estavam em falso trabalho de parto. No entanto, cabe esclarecer 
que não foram acessados os prontuários dos pacientes para comprovação da situação gestacional.

No estudo realizado com primigestas adolescentes no terceiro trimestre de gravidez, o falso trabalho de parto foi um dos motivos mais relatados por gestantes que não conseguiram ser admitidas, de imediato, nas instituições. A motivação que as leva a procurar a maternidade precocemente pode estar relacionada com a dificuldade para reconhecer o momento propício da procura do atendimento profissional na hora de parir $^{(24)}$.

O momento do parto refere-se a uma situação desconhecida e que não se tem controle. Para tanto, demanda cuidados específicos para que se tenha condições de distinguir entre falso e verdadeiro o trabalho de parto. Este cuidado é imprescindível nos momentos que antecedem o parto e ao nascimento, já que o estado emocional da parturiente, muitas vezes, mostra-se extremamente vulnerável às condições apresentadas pelo ambiente e pelas relações com as pessoas ao seu redor, pois a ansiedade também toma conta de quem está próximo ${ }^{(13)}$.

Por meio dos discursos apreendeu-se neste estudo que cada mulher vivencia distintamente esse processo, uma vez que há interação dos fatores emocionais, fisiológicos, sociais e culturais que garantem caráter individual do trabalho de parto.

\section{CONSIDERAÇÕES FINAIS}

A fenomenologia social de Alfred Schütz permitiu a compreensão das ações das mulheres que vivenciaram a maternidade em contexto particular, respondendo às indagações do estudo.

A análise dos dados possibilitou compreender a influência da dor na complexidade do trabalho de parto, tendo em vista sua subjetividade e multifatoriedade, que se entrelaçam e se confundem. Também evidenciou que nem sempre é possível racionalizar acerca da dor em razão do meio sociocultural no qual a gestante está inserida.

Face à lacuna existente entre a última consulta do pré-natal e a resolução do parto, é imprescindível que a gestante seja acolhida pelo serviço de saúde com assistência do profissional enfermeiro, que é capacitado para cuidar de maneira única e particular dessa mulher numa condição de vulnerabilidade frente à dor e às incertezas do momento.

As limitações do estudo referem-se ao delineamento qualitativo, que não permite a generalização dos resultados, mas permite compreender os indivíduos em seu próprio contexto. Além disso, há que se considerar também que não foram consultadas informações de prontuário médico para coletar dados referentes à gestação e trabalho de parto.

Por fim, os resultados poderão contribuir para a reflexão sobre a prática dos enfermeiros, assistências e aprimoramento do processo de trabalho direcionado a uma assistência integral e humanizada do pré-natal. 


\section{REFERÊNCIAS}

1. Mafetoni RR, Shimo AKK. Efeitos da acupressão na evolução do parto e taxa de cesárea: ensaio clínico randomizado. Rev Saúde Pública [Internet]. 2015 [acesso em: 4 out 2016];49:9. Disponível em: http://www.scielosp.org/pdf/rsp/v49/pt_0034-8910-rsp-S0034-89102015049005407.pdf.

2. Sanfelice C, Ressel LB, Stumm KE, Pimeta LF. Crenças e práticas do período gestacional. Saúde. 2013;39(2):35-48. 3. Pinheiro CB, Bittar CML. Expectativas, percepções e experiências sobre o parto normal. Relato de um grupo de mulheres. Fractal Rev Psicol. 2010;25(3):585-602.

4. Guerreiro EM, Rodrigues DP, Silveira MAM, Lucena NBF. O cuidado pré-natal na atenção básica de saúde sob o olhar de gestantes e enfermeiros Rev Min Enferm. 2012;16(3):315-23.

5. Matos DS, Rodrigues MS, Rodrigues TS. Atuação do enfermeiro na assistência ao pré-natal de baixo risco na estratégia saúde da família em um município de Minas Gerais. Rev Enferm Minas Gerais. 2013;16(1):18-33.

6. Leifer G. Enfermagem obstétrica. 11a ed. Rio de Janeiro: Elsevier; 2013.

7. Minayo MCS. O desafio do conhecimento. Pesquisa qualitativa em saúde. 13a ed. São Paulo: Hucitec; 2013. 8. Jesus MCP, Capalbo C, Merighi MAB, Oliveira DM, Tocantins FR, Rodrigues BMRD, et al. A fenomenologia social de Alfred Schütz e sua contribuição para a enfermagem. Rev Esc Enferm USP. 2013;47(3):736-41.

9. Schütz A. Sobre fenomenologia e relações sociais. Petrópolis: Vozes; 2012.

10. Holloway I, Wheller S. Phenomenology. In: Holloway I, Wheller S, Organizadores. Qualitative research in Nursing and Healthcare. 3rd ed. Oxford: John \& Son; 2013.

11. Santos LM, Pereira SSC. Vivências de mulheres sobre a assistência recebida no processo parturitivo. Physis. 2012;22(1):77-97.

12. Guerra MJ, Braga MC, Quelhas I, Silva R. Promoção da saúde mental na gravidez e no pós-parto. Rev Port Enferm Saúde Mental. 2014;(Spe 1):117-24.

13. Adams SS, Eberhard-Gran M, Eskild A. Fear of childbirth and duration of labour: a study of 2206 women with intended vaginal delivery. BJOG. 2012;119(10):1238-46.

14. Souza VB, Roecker S, Marcon SS. Ações educativas durante a assistência pré-natal: percepção de gestantes atendidas na rede básica de Maringá-PR. Rev Eletr Enferm [Internet]. 2011 [acesso em: 13 ago 2016];13(2):199-210. Disponível em: http://www.fen.ufg.br/revista/v13/n2/v13n2a06.htm.

15. Scarton J, Prates LA, Barreto CN, Pompeu KC, Castiglione CM, Ressel LB. O cuidado de enfermagem no trabalho de parto e parto: vivências de puérperas primíparas. Rev Enferm UFPE. 2014;8(6):1820-3.

16. Duarte SJH. Motivos que levam as gestantes a fazerem o pré-natal: um estudo das representações sociais. Cienc Enferm. 2012;18(2):75-82.

17. Souza TA, Brito MEM, Frota AC, Nunes JM. Gravidez na adolescência: percepções, comportamentos e experiências de familiares. Rev Rene. 2012; 13(4):794-84.

18. Orief YI, Farghaly NF, Ibrahim MIA. Use of herbal medicines among pregnant women attending family health centers in Alexandria. Middle East Fertil Soc J. 2014;19(1):42-50.

19. Silva ALS, Almeida LCG. Vivência de mulheres frente à peregrinação para o parto. Rev Eletron Atualiza Saúde. 2015;2(2):7-19.

20. Almeida NAM, Medeiros M, Souza MR. Perspectivas de dor do parto normal de primigestas no período pré-natal. Texto Contexto Enferm. 2012;21(4):819-27.

21. Bourke J. Childbirth in the UK: suffering and citizenship before the 1950s. Lancet. 2014; 383(9925):1288-9.

22. Ternström E, Hildingsson I, Haines $H$, Rubertsson C. All access types pregnant women's thoughts when assessing fear of birth on the Fear of Birth. Women Birth. 2016;29(3):e44-9.

23. Pereira RR, Franco SC, Baldin N. A dor e o protagonismo da mulher na parturição. Rev Bras Anestesiol. 2011;61(3):376-88.

24. Mota EM, Oliveira MF, Victor JF, Pinheiro AKB. Sentimentos e expectativas vivenciados pelas primigestas adolescentes com relação ao parto. Rev Rene. 2011;12(4):692-8. 